\title{
Long-term results of the Heller-Dor operation with intraoperative manometry for the treatment of esophageal achalasia
}

\author{
Sandro Mattioli, MD, ${ }^{\text {a }}$ Alberto Ruffato, MD, $\mathrm{PhD},{ }^{\mathrm{a}}$ Marialuisa Lugaresi, $\mathrm{MD}, \mathrm{PhD},{ }^{\text {a }}$ Vladimiro Pilotti, $\mathrm{MD},{ }^{\mathrm{a}}$ \\ Beatrice Aramini, MD, ${ }^{\mathrm{b}}$ and Frank D'Ovidio, $\mathrm{MD}, \mathrm{PhD}^{\mathrm{b}}$
}

Objective: Quality of outcome of the Heller-Dor operation is sometimes different between studies, likely because of technical reasons. We analyze the details of myotomy and fundoplication in relation to the results achieved over a 30-year single center's experience.

\begin{abstract}
Methods: From 1979-2008, a long esophagogastric myotomy and a partial anterior fundoplication to protect the surface of the myotomy was routinely performed with intraoperative manometry in 202 patients ( 97 men; median age, 55.5 years; interquartile range, 43.7-71 years) through a laparotomy and in 60 patients (24 men; median age, 46 years; interquartile range, $36.2-63$ years) through a laparoscopy. The follow-up consisted of periodical interview, endoscopy, and barium swallow, and a semiquantitative scale was used to grade results.
\end{abstract}

Results: Mortality was 1 of 202 in the laparotomy group and 0 of 60 in the laparoscopy group. Median follow-up was 96 months (interquartile range, 48-190.5 months) in the laparotomy group and 48 months (interquartile range, 27-69.5 months) in the laparoscopy group. At intraoperative manometry, complete abolition of the high-pressure zone was obtained in $100 \%$. The Dor-related high-pressure zone length and mean pressure were $4.5 \pm 0.4 \mathrm{~cm}$ and $13.3 \pm 2.2 \mathrm{~mm} \mathrm{Hg}$ in the laparotomy group and $4.5 \pm 0.5 \mathrm{~cm}$ and $13.2 \pm 2.2 \mathrm{~mm} \mathrm{Hg}$ in the laparoscopy group $(P=.75)$. In the laparotomy group poor results $(19 / 201[9.5 \%])$ were secondary to esophagitis in $15(7.5 \%)$ of 201 patients (in 2 patients after 184 and 252 months, respectively) and to recurrent dysphagia in $4(2 \%)$ of 201 patients, all with end-stage sigmoid achalasia. In the laparoscopy group $2(3.3 \%)$ of 60 had esophagitis.

Conclusions: A long esophagogastric myotomy protected by means of Dor fundoplication cures or substantially reduces dysphagia in the great majority of patients affected by esophageal achalasia and effectively controls postoperative esophagitis. Intraoperative manometry is likely the key factor for achieving the reported results.

(J Thorac Cardiovasc Surg 2010;140:962-9)

The laparoscopic Heller myotomy associated with anterior Dor fundoplication is one of the more frequently adopted surgical techniques for treating esophageal achalasia. ${ }^{1-4}$ Very satisfactory results have been obtained in a large single-institution case series. ${ }^{5}$ A review of articles in the English-language literature dedicated to surgical intervention for achalasia published between 1999 and 2009 (http://www.ncbi.nlm.nih.gov/pubmed) identified the Heller-Dor technique as the procedure of choice in $76(60$. $3 \%$ ) of 126 articles. However, the same review also demonstrated that surgeons $s^{2,3,6,7}$ are not in agreement on several aspects of this surgical technique.

\footnotetext{
From the Division of Thoracic Surgery, ${ }^{\text {a }}$ Center for the Study and Therapy of Diseases of the Esophagus, Alma Mater Studiorum-University of Bologna and GVM Care and Research, Cotignola, Italy; the PhD Course in Pneumo-Cardio-Thoracic Scien-

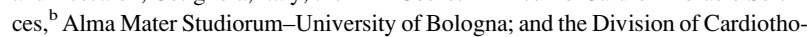
racic Surgery, Columbia University, New York, NY.

Disclosures: None.

Read at the 90th Annual Meeting of The American Association for Thoracic Surgery, Toronto, Ontario, Canada, May 1-5, 2010.

Received for publication April 30, 2010; revisions received July 11, 2010; accepted for publication July 19, 2010; available ahead of print Sept 9, 2010.

Address for reprints: Sandro Mattioli, MD, Department of Surgery and Organs Transplantation, Faculty of Medicine, Alma Mater Studiorum-University of Bologna, Via G. Massarenti 9, 40138 Bologna, Italy (E-mail: sandro.mattioli@unibo.it).

0022-5223/\$36.00

Copyright (c) 2010 by The American Association for Thoracic Surgery doi: $10.1016 /$ j.jtcvs. 2010.07 .053
}

In the late 1970s, we adopted a myotomy extended to the gastric lesser curvature for the surgical treatment of esophageal achalasia, which was associated with the original antireflux procedure created by Dor. ${ }^{8}$ Myotomy and fundoplication were performed under the control of intraoperative manometry. Follow-up occurred regularly after surgical intervention. ${ }^{9,10}$ Recently, we reviewed our database for the years 1979-2009 and paid particular attention to the data collected with intraoperative esophageal manometry in an attempt to contribute to the clarification of some of the debated technical details of the Heller-Dor operation. We compared the results obtained with the same technique standardized by means of intraoperative manometry performed through either a laparotomy or laparoscopy.

\section{MATERIALS AND METHODS}

Diagnosis of achalasia was performed routinely with barium swallow, endoscopy, and esophageal manometry. A total of 262 patients who underwent the Heller-Dor operation in the first instance of achalasia in the period between January 1979 and December 2008 were considered; 202 patients (97 men; median age, 55.5 years; interquartile range [IQR], 43.7-71 years) underwent a laparotomy, and 60 patients ( 24 men; median age, 46 years; IQR, 36.2-63 years) underwent a laparoscopic procedure. Since 2005, laparoscopy has become the routine procedure. ${ }^{10}$ A preoperative condition of sigmoid esophagus, diagnosed when the diameter of the esophagus was greater than $6 \mathrm{~cm}^{11}$ and the distal esophagus was kinked toward the left outside of the esophageal axis, was present in $33(16.3 \%)$ of 202 patients in the 


\author{
Abbreviations and Acronyms \\ $\mathrm{HPZ}=$ high-pressure zone \\ $\mathrm{IQR}=$ interquartile range \\ LES $=$ lower esophageal sphincter \\ $\mathrm{RE}=$ reflux esophagitis
}

laparotomy group and in $7(11.7 \%)$ of 60 patients in the laparoscopy group. Eighteen $(54.6 \%)$ of 33 patients in the laparotomy group and $7(100 \%)$ of 7 patients in the laparoscopy group underwent the Heller-Dor procedure associated with the pull-down technique. ${ }^{11}$ Thirty-three $(16.3 \%)$ patients from the laparotomy group and $7(18.3 \%)$ patients from the laparoscopy group underwent endoscopic treatment before surgical intervention.

\section{Radiology}

Timed barium swallow was performed according to a standardized protocol to calculate the modifications of the esophageal diameter and the residual barium column induced by the surgical therapy. ${ }^{12,13}$ We previously demonstrated that the esophageal diameter and residual barium column decrease substantially during the first 3 years after the operation and not later. ${ }^{9}$ Thus to compare the variations of the radiologic parameters after the laparotomic or laparoscopic Heller-Dor procedure, we considered postoperative barium swallows performed within 12 and 36 months (the last one) after the operation. For the present study, we considered the cases in which x-ray films were available for a new measurement according to the protocol.

\section{Operative Techniques}

The open and laparoscopic techniques were extensively described and presented at the annual congress of the American College of Surgeons (Thoracic Surgery Films and Videos Session) in $1981^{14}$ and $1994 .{ }^{15}$

In brief, the key points of the technique adopted for the initial stages of achalasia (for sigmoid esophagus, see below) were as follows: (1) isolation of the gastroesophageal junction limited to the anterior aspect and avoiding the division of the short gastric vessels; (2) extension of the myotomy to the gastric lesser curvature; (3) suturing of the apex of the fundus to the apex of the myotomy; and (4) fixation of the anterior aspect of the gastric fundus to the 2 edges of the myotomy with 2 rows of 6 to 8 stitches each.

If the manometric value of the pressure induced by the fundoplication was less than the standard value, additional stitches were applied to wrap the fundus $270^{\circ}$ around the esophagus. ${ }^{8}$ In cases of sigmoid esophagus, the pull-down technique ${ }^{11}$ was used in addition to the standard technique. The gastroesophageal junction was isolated for $360^{\circ}$, and the lower mediastinal esophagus was mobilized for at least $6 \mathrm{~cm}$. Before performing the Heller-Dor procedure, 2 or more U-shaped intramuscular stitches were applied at the level of the esophageal kinking on the right side of the esophagus to pull down and rotate the right side of the gastroesophageal junction with a tie of the sutures (pull-down technique).

\section{Intraoperative Manometry}

From 1978 to the present, intraoperative manometry was performed with 3 different recorders, infusion pumps, and probes. In the first phase we used a multilumen probe (Arndorfer Medical Specialties, Greensdale, Wis) perfused at a rate of $0.5 \mathrm{~mL} / \mathrm{min}$ with distilled water by a pneumohydraulic low-compliance capillary infusion system (Arndorfer Medical Specialties) and connected to a Beckman R 612 polygraph (Beckman Instruments, Schiller Park, Ill). In the second phase the examination was performed with a multilumen probe (MUI 500005; Mui, Inc, Ontario, Canada), which was perfused with a low-compliance pneumohydraulic pump $(0.6 \mathrm{~mL} / \mathrm{min}$; Mui, Inc) and connected to a multichannel polygraph (EP I2 ESAOTE; Bi- omedica, Florence, Italy). Since 2003, we have used a disposable multilumen probe (Medtronic 9012P1221; Medtronic, Inc, Minneapolis, Minn) perfused with a low-compliance pneumohydraulic pump $(0.6 \mathrm{~mL} / \mathrm{min}$; Mui, Inc) and connected to a multichannel polygraph (Polygraf ID; Medtronic, Inc).

The distal high-pressure zone (HPZ) pressures and profiles were recorded by the 4 radial open tips with the slow pull-through technique, withdrawing the catheter in steps at $1 \mathrm{~cm} / 10 \mathrm{~s}$. Intraoperative manometry was performed and interpreted according to previously described standard criteria. ${ }^{16}$ Manometric pull-through is repeated at different phases of the surgical procedure: (1) once the left liver lobe is retracted on the right side, the gastroesophageal junction and the anterior vagus nerve are isolated (Figure 1, $A)$; (2) after the esophageal side myotomy; (3) after the gastric side myotomy (Figure 1,B); and (4) at the end of the Dor procedure (Figure 1,C). During the myotomy and Dor phases, the pull-through recording is repeated until the reference values (residual HPZ pressure and fundoplication pressure and length) are obtained. These manometric gold standards were determined in the first phase of our experience. ${ }^{8,16}$ Initial, residual, and final HPZ pressures are expressed as the means of 4 maximal end-expiration pressures measured by the 4 radial open tip probes.

In laparoscopic surgery the pneumoperitoneal pressure $(11-12 \mathrm{~mm} \mathrm{Hg})$ should be subtracted from these means. Before and during the operation, atropine or any other anticholinergic drugs are avoided. The first and second phases of the experience were useful to standardize the manometric examination and to determine reference pressures and the length of the antireflux procedure ${ }^{16}$ In the present study we considered the patients operated on in the last 2 phases, when the technical characteristics of recorder, infusion pump, and multilumen probe were similar and the reference values were the same.

\section{Follow-up}

The institutional review board of the University of Bologna approved the use of the database from the Center for the Study and Therapy of Diseases of the Esophagus for research purposes.

Patients were followed according to a protocol previously described in detail. ${ }^{9,12}$ In summary, at given intervals, patients underwent an outpatient examination, including endoscopy, barium swallow, esophageal manometry, and other tests, if needed. Dysphagia, gastroesophageal reflux symptoms, and reflux esophagitis (RE) assessed by means of endoscopy were graded according to semiquantitative scales (Table 1). In the first 20 years, RE was assessed according to the modified Savary-Miller endoscopic classification and according to the Los Angeles classification $2003 .^{10}$

\section{Statistical Analysis}

Data are expressed as median values and IQRs for continuous variables unless otherwise stated and as counts or proportions (as percentages) for categorical variables. The Wilcoxon signed-rank test was used to compare preoperative and postoperative radiologic data between groups. The $\chi^{2}$ test was used to compare categorical variables, and a Student's $t$ test for unpaired data was used to evaluate manometric results. Statistical analyses were performed with the SPSS 13.0 software package (SPSS, Inc, Chicago, Ill).

\section{RESULTS}

One $(0.4 \%)$ patient died (after 2 previous operations for tetralogy of Fallot) in the laparotomy group. In the laparoscopy group immediate conversion to laparotomy occurred in $2(3.3 \%)$ of 60 patients as a result of bleeding, and no inhospital deaths were reported.

Esophageal mucosal perforation occurred during the myotomy in $6(3 \%)$ of 202 patients undergoing laparotomies, 


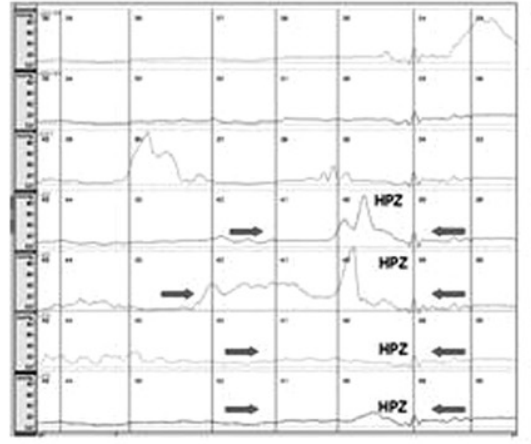

A

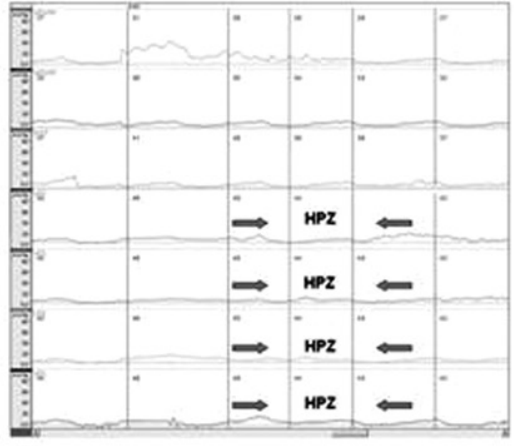

B

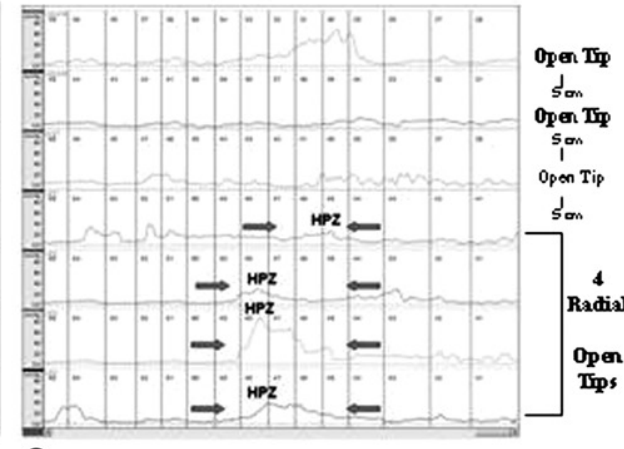

C

FIGURE 1. Intraoperative manometry performed with a multilumen probe ( 3 proximal, $5 \mathrm{~cm}$ apart, 4 radial open tips) using the slow pull-through technique, withdrawing the catheter in steps at $1 \mathrm{~cm} / 10 \mathrm{~s}$. High-pressure zone (HPZ) profiles were recorded by 4 radial open tips after opening of the anterior aspect of the phrenoesophageal membrane (pressure, $15.3 \mathrm{~mm} \mathrm{Hg}$; length, $4 \mathrm{~cm}$; A), the esophagogastric myotomy was completed (pressure, 0; B), and the distal HPZ was produced by the Dor fundoplication (pressure, $13.5 \mathrm{~mm} \mathrm{Hg}$; length, $4 \mathrm{~cm}$; ).

always on the gastric side of the myotomy; 2 patients had previously undergone endoscopic dilation. In the laparoscopy group perforation occurred in $3(5 \%)$ of 60 patients. All patients underwent endoscopic dilation before surgical intervention. Mucosal perforation was always recognized and repaired intraoperatively without any consequence.

In the laparotomy group morbidities occurred in 13 $(6.5 \%)$ of 202 patients: 3 intraoperative hemorrhages in 2 cases that required splenectomy; 2 patients with pneumothorax; 3 patients who underwent the pull-down technique with transient dysphagia; and 5 patients with minor complications. In the laparoscopy group morbidities occurred in 5 $(8.3 \%)$ of 60 patients: 1 patient with a hemorrhage requiring a revision splenectomy; 2 patients with atrial fibrillation; 1 patient with pneumothorax; and 1 patient who underwent the pull-down technique with revision of the fundoplication because of difficult esophageal emptying. In $16(6 \%)$ of 262 cases, a $270^{\circ}$ wrapping around the esophagus was necessary to increase the pressure of the fundoplication to the reference value. In $100 \%$ of these cases, the short vessels had been previously divided for some reason.

Of the 262 patients, $99.6 \%$ were followed; median follow-ups were 96 months (IQR, 48-190.5 months) and 48 months (IQR, 27-69.5 months) for the laparotomy (201 patients) and laparoscopy groups (60 patients), respectively.

Over the 30-year study period, $7(2.7 \%)$ patients died of causes unrelated to achalasia, and $12(4.6 \%)$ patients underwent a second operation for the following: esophagectomy

TABLE 1. Results of surgical therapy for esophageal achalasia: Dysphagia, reflux symptoms, and reflux esophagitis are graded according to semiquantitative scales (see the text)

\begin{tabular}{|c|c|c|c|}
\hline & & $\begin{array}{l}\text { Laparotomy } \\
201 \text { patients }\end{array}$ & $\begin{array}{l}\text { Laparoscopy } \\
60 \text { patients }\end{array}$ \\
\hline D0 (absent) & \multirow[t]{3}{*}{ Excellent } & \multirow[t]{3}{*}{$113(56.2 \%)$} & \multirow[t]{3}{*}{$30(50 \%)$} \\
\hline RSO (absent) & & & \\
\hline RE0 (normal) & & & \\
\hline D1 (sticking of solid foods or liquids $2-4$ times a month) & \multirow[t]{3}{*}{ Good } & \multirow[t]{3}{*}{$55(27.4 \%)$} & \multirow[t]{2}{*}{$27(45 \%)$} \\
\hline $\begin{array}{l}\text { RS1 (spontaneous or postural retrosternal heartburn or pain and or } \\
\text { regurgitation occurring 2-4 times a month) }\end{array}$ & & & \\
\hline RE0 (normal) & & & \\
\hline D2 (sticking of solid foods or liquids $2-4$ times a week) & \multirow[t]{3}{*}{ Fair } & \multirow[t]{3}{*}{$14(6.9 \%)$} & \multirow[t]{3}{*}{$1(1.7 \%)$} \\
\hline $\begin{array}{l}\text { RS2 (spontaneous or postural retrosternal heartburn or pain or regurgitation } \\
\text { occurring 2-4 times a week associated or not with occasional aspiration) }\end{array}$ & & & \\
\hline RE1 (hyperemia, edema, and/or histology positive for reflux esophagitis) & & & \\
\hline D3 (sticking of solid foods or liquids on a daily basis) & \multirow[t]{3}{*}{ Poor } & \multirow[t]{3}{*}{$19(9.5 \%)$} & \multirow[t]{3}{*}{$2(3.3 \%)$} \\
\hline $\begin{array}{l}\text { RS3 (spontaneous or postural retrosternal heartburn or pain and regurgitation } \\
\text { occurring on a daily basis associated or not with frequent aspiration) }\end{array}$ & & & \\
\hline $\begin{array}{l}\text { RE2-3-4 or Los Angeles A-B (single or multiple nonconfluent and confluent } \\
\text { erosions, deep ulcers, stenosis, Barrett's esophagus) }\end{array}$ & & & \\
\hline
\end{tabular}



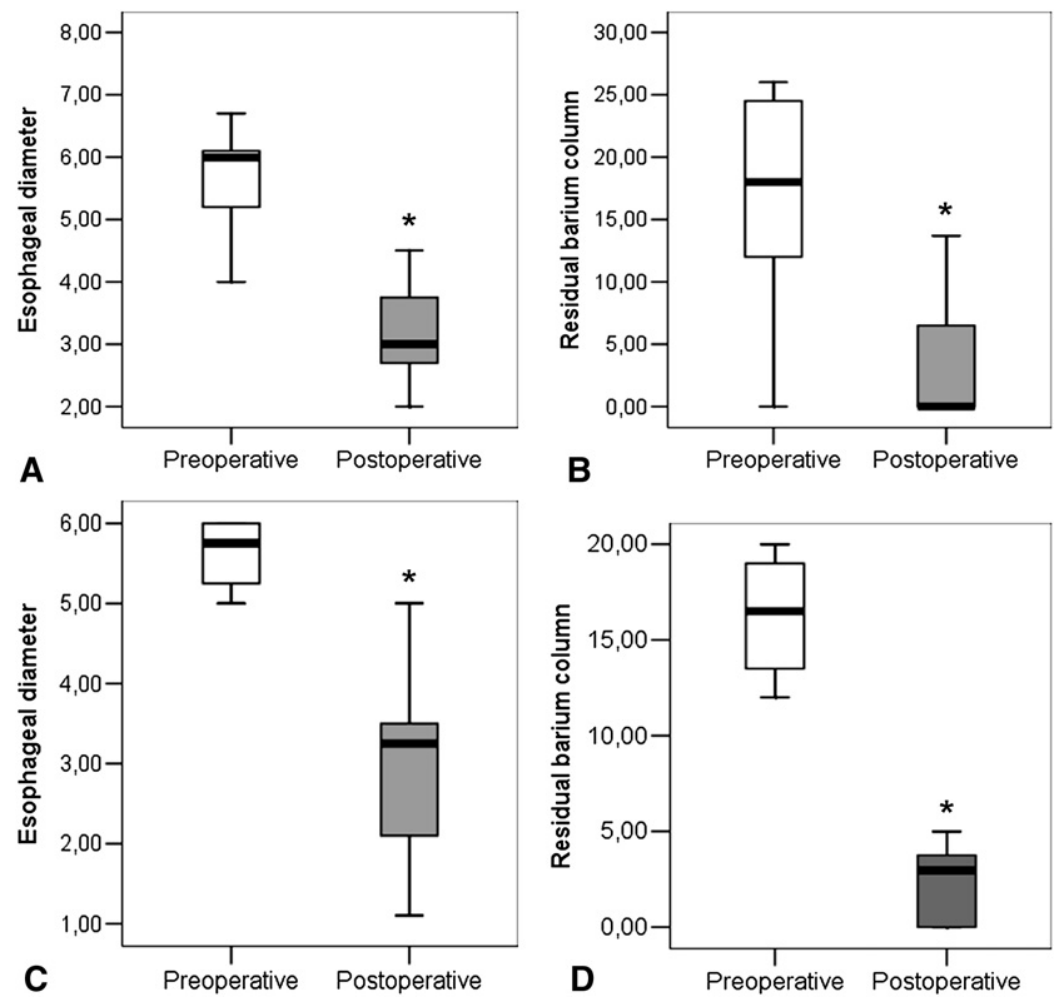

FIGURE 2. The esophageal diameter and residual barium column were measured before and within 36 months after surgical intervention. In the graphic boxplot representation values are expressed in centimeters. Boxes indicate interquartile ranges, the horizontal bar is the median measurement, and whiskers indicate $95 \%$ confidence intervals for the mean. The laparotomy group's preoperative and postoperative esophageal diameter $(P=.001, \mathrm{~A})$ and esophageal residual barium column $(P=.001, \mathrm{~B})$ are shown, as are the laparoscopy group's preoperative and postoperative esophageal diameter $(P=.001, \mathrm{C})$ and esophageal residual barium column $(P=.001, \mathrm{D})$.

for epidermoid carcinoma $(\mathrm{n}=3)$, Barrett's adenocarcinoma $(\mathrm{n}=1)$, stasis esophagitis $(\mathrm{n}=2)$, severe dysphagia $(\mathrm{n}=1)$, reposition of slipped fundoplication $(n=2)$, Roux-en-Y distal gastrectomy and fundoplication for severe RE $(n=2)$, and Roux-en-Y distal gastrectomy for cancer of the gastric antrum $(n=1)$. The evaluation of the results of the Heller-Dor operation was discontinued at the time of death or second operation. The development of cancer was not considered a negative consequence of the myotomy.

\section{Intraoperative Manometry}

We considered the last 162 manometric traces performed. Several manometric pull-through procedures were usually necessary before achieving the complete abolition of the HPZ with myotomy (manometric zero). A perfect myotomy at the first manometric pull was rare. Even thin bridges of muscular fibers of the inner circular muscle could produce pressure, which were short but clearly visible in the traces. Myotomy achieved the complete abolition of the HPZ in $100 \%$ of the patients in both groups. The Dor-related HPZ length and mean pressure were $4.5 \pm 0.4 \mathrm{~cm}$ and $13.3 \pm$ $2.2 \mathrm{~mm} \mathrm{Hg}$, respectively, in the laparotomy group and $4.5 \pm 0.5 \mathrm{~cm}$ and $13.2 \pm 2.2 \mathrm{~mm} \mathrm{Hg}$, respectively, in the laparoscopy group $(P=.75)$.

\section{Radiology}

Comparison of the radiologic examinations before the operation and within 36 months after the operation was performed in 152 patients in the laparotomy group and 29 patients in the laparoscopy group. The median esophageal diameter and median height of the barium column were significantly decreased in both groups (Figure 2). Interestingly, the decrease in the percentage of both parameters was nearly the same. In the group of patients submitted to the open transabdominal operation, we found a $50 \%$ decrease in the median diameter of the esophagus (from $6 \mathrm{~cm}$ [IQR, 5-6.1 $\mathrm{cm}$ ] to $3 \mathrm{~cm}$ [IQR, 2.7-3.7 cm], $P=.001$ ] and a $94.4 \%$ decrease of the barium column (from $18 \mathrm{~cm}$ [IQR, 11.1-24.7 $\mathrm{cm}$ ] to $1 \mathrm{~cm}$ [IQR, $0-6.5 \mathrm{~cm}$ ], $P=.001$ ). For patients in the laparoscopy group, we found a $43.8 \%$ decrease in the median diameter of the esophagus (from $5.7 \mathrm{~cm}$ [IQR, $5.5-6 \mathrm{~cm}$ ] to $3.2 \mathrm{~cm}$ [IQR, 2.1-3.5 cm], $P=.001)$ and an $86.7 \%$ decrease of the barium column (from $15 \mathrm{~cm}$ [IQR, $12-18 \mathrm{~cm}$ ] to $2 \mathrm{~cm}$ [IQR, $0-3.7 \mathrm{~cm}], P=.001)$.

\section{Dysphagia}

In the laparotomy group dysphagia was absent (D0) in $132(65.7 \%)$ of 201 patients. Dysphagia was episodic (D1) in $50(24.8 \%)$ patients, moderate (D2) in $15(7.5 \%)$ 
patients, and severe (D3) in $4(2 \%)$ patients, of whom 3 had preoperative sigmoid esophagus. Three patients (sigmoid achalasia) who had epidermoid cancer complained of moderate (D2) dysphagia.

In the laparoscopy group dysphagia was absent (D0) in 49 $(81.7 \%)$ of 60 patients. Ten $(16.6 \%)$ patients complained of episodic (D1) dysphagia, and $1(1.7 \%)$ patient had moderate (D2) dysphagia. None of the patients in the laparoscopy group reported relapse of severe (D3) dysphagia. Moderate (D2) and severe dysphagia (D3) appeared in both groups at a mean time of 23.7 months (range, 12-72 months) after the operation.

\section{Gastroesophageal Reflux Symptoms}

In the laparotomy group postoperative gastroesophageal reflux symptoms were absent (RS0) in $140(69.6 \%)$ of 201 patients and were recorded 2 to 4 times a month and graded as slight (RS1) in $42(20.9 \%)$ patients, moderate (RS2) in $13(6.5 \%)$ patients, and severe (RS3) in $6(3 \%)$ patients. In the laparoscopy group no reflux symptoms (RS0) were recorded in $46(76.7 \%)$ patients, whereas 11 $(18.3 \%)$ patients reported slight reflux symptoms (RS1), 1 $(1.7 \%)$ patient reported moderate (RS2) reflux symptoms, and $2(3.3 \%)$ patients presented with severe reflux symptoms (RS3).

\section{Reflux Esophagitis}

The onset of erosive or ulcerative RE, which was absent before the operation, occurred in $15(7.5 \%)$ of 201 patients in the laparotomy group (median age, 62 years; IQR, 54-71 years), with 9 cases of moderate esophagitis (1 single erosion or Los Angeles grade A) and 6 severe cases (confluent erosion, ulcer, or Los Angeles grade B). RE was diagnosed endoscopically at a mean of 74.8 months (range, 12-252 months) after the operation. The majority of these patients did not have any evidence of esophagitis at early postoperative endoscopies. In patients treated with the laparoscopic approach, the onset of postoperative RE was detected in 2 $(3.3 \%)$ patients after a mean period of 17 months. Analysis of the 17 patients ( 9 [53\%] women; median age, 61.5 years; IQR, 49.5-71 years) with postoperative RE after laparotomic and laparoscopic surgery revealed the following: (1) in 2 patients the early onset of esophagitis was due to slipping of the Dor fundoplication; (2) in 6 patients, in whom reflux symptoms appeared early and esophagitis was diagnosed within 24 months after the operation, a past history of epigastric pain and heartburn, ulcer-like dyspepsia, and Helicobacter pylori infection (5/6) was reported; (3) in 2 patients erosive esophagitis appeared after 184 and 252 months at 81 and 69 years of age, respectively; and (4) in 7 patients RE was diagnosed at least 36 months after the operation in patients with a normal gastric profile at preoperative endoscopy, no history of dyspeptic symptoms, and normal barium swallow. In 2 young women esophagitis appeared with reflux symptoms after a significant increase in body weight.

The overall results were graded according to a semiquantitative scale and are reported in Table 1.

We obtained excellent (D0-1, RS0-1, and E0) results and good results in $168(83.6 \%)$ patients in the laparotomy group and 57 (95\%) patients in the laparoscopy group and fair results (D2, RS2, and E1) in $14(6.9 \%)$ patients in the laparotomy group and $1(1.7 \%)$ patient in the laparoscopy group. Nineteen $(9.5 \%)$ patients in the laparotomy group and $2(3.3 \%)$ patients in the laparoscopy group had insufficient results (D3, RS3, E2-3, or Los Angeles A-B). Previous endoscopic treatments did not influence the outcome.

\section{DISCUSSION}

In surgical intervention for achalasia, the main points of debate are the extension of the myotomy onto the lesser gastric curvature ${ }^{17}$ and the pros and cons of adding an antireflux procedure to the myotomy. ${ }^{1,2,4,8}$ The Dor and Toupet fundoplications are preferred to the $360^{\circ}$ Nissen fundoplication because they produce less postoperative dysphagia. ${ }^{18}$ The majority of surgeons prefer an anterior wrap, ${ }^{4,18,19}$ called the Dor fundoplication, although the operative techniques reported in several articles ${ }^{2,3,6}$ differ from the original.

Eponyms are frequently used in honor of distinguished surgeons who promoted new operations. However, the original technique can be substantially modified over time. ${ }^{20}$ Our group adopted the Heller-Dor operation 30 years ago on the basis of very precise principles of surgical physiology. In the 1970s, we carefully reviewed the results obtained from 2 groups of patients. ${ }^{12}$ In the first group we performed a long abdominal Heller myotomy, in about $20 \%$ of cases associated with the Lortat-Jacob antireflux procedure (suture of the right margin of the gastric fundus to the left margin of the esophagus). ${ }^{20}$ In the second group we used a transthoracic myotomy, as proposed by Ellis and colleagues, ${ }^{21}$ which was limited to the gastric side to prevent postoperative reflux. We concluded that (1) a long esophagogastric myotomy would abolish the lower esophageal sphincter (LES) but would predispose the patient to massive gastroesophageal reflux; (2) calibration of the myotomy, as proposed by Dr Ellis, was difficult in the absence of a peculiar experience; and (3) apposition of the left liver to the nude myotomy could lead to fibrosis and scarring, which was eventually favored by suboptimal hemostasis or subclinical leakage of the mucosa. ${ }^{12}$ In the same period it was postulated that the U-shaped fibers of the gastric lesser curvature tiled with the sling fibers of the Helvetius collar formed a sphincter-like complex. ${ }^{22}$ In consequence, we decided to perform a long esophagogastric myotomy to abolish the distal HPZ together with an anterior fundoplication to protect the raw surface of the myotomy. This was efficient, but it was not enough to avoid the risk of hypercompetency. ${ }^{12,18}$ Thus 
the Dor fundoplication seemed to fit our purposes, and we carefully duplicated the original technique. ${ }^{8}$ Intraoperative manometry was the compass of our 30 years of experience. It was performed in all patients who underwent operations to verify the effects on the LES of the division of the fibers of the muscular layers at the gastroesophageal junction and to understand how to perform a good, calibrated Dor fundoplication. We showed that, after esophageal myotomy, the residual pressure corresponding to the U-shaped and sling fibers of the gastric side of the gastroesophageal junction ranged from low to relatively high pressures. ${ }^{23}$ These manometric data could explain the variability of the results obtained with the transthoracic myotomy limited distally to prevent reflux. ${ }^{21,24}$ In addition, we saw in the tracings that even thin bridges of circular muscle between the 2 edges of the myotomy would produce significant residual pressure that disappeared after their division. These observations were confirmed by others. ${ }^{25}$ The myotomy should be very meticulous and extend laterally between mucosa and muscle. We also achieved indications for properly performing the Dor fundoplication. After comparing the intraoperative values of pressure and length of the fundoplication with the postoperative manometric values and the long-term results, we obtained reference parameters that we have duplicated in every patient since. ${ }^{8}$

Another important lesson learned concerned the effects of the division of the gastrosplenic ligament and of the short gastric vessels on the final pressure of the Dor fundoplication, which was performed in some cases when the gastrosplenic ligament and the short vessels appeared too tight. These maneuvers were not part of the original Dor technique. ${ }^{8,20}$ In particular, after sectioning the short vessels, we documented a decrease in the final pressure of the fundoplication to less than 8 to $10 \mathrm{~mm} \mathrm{Hg}$, which is too low for our standards. ${ }^{8}$

The Heller-Dor procedure in our operating rooms has been standardized for at least 20 years. In this period we produced several reports looking at different aspects of surgical intervention for achalasia. In the present study we interpreted the results achieved with this operation performed through a laparotomy or a laparoscopy in light of the data of intraoperative manometry, the method we adopted since the beginning, to research first and to standardize later in an attempt to provide readers with new information that is hopefully useful for their daily practice.

We abolished the HPZ in all patients, comprising those previously submitted to pneumatic dilation or Botox injection, although with some difficulty. The mean length of the HPZ produced by the fundoplication was $4 \mathrm{~cm}$ located just below the cardia, whereas the fundoplication was generally long at $6 \mathrm{~cm}$ or more. The length and pressure of the Dor fundoplication at the end of the procedure were equal through a laparotomy or a laparoscopy, and the standard deviations of the means were minimal. We speculate that the
Dor fundoplication works by means of the tension created by the 2 rows of stitches and the spleen; the short vessels must not be divided to obtain an efficient antireflux barrier.

Relapse of significant dysphagia occurred in $2 \%$ of the laparotomy group and did not occur in the laparoscopy group. Residual dysphagia was always related to a condition of sigmoid esophagus. In the last period of the study, we routinely adopted the pull-down technique to recreate a vertical axis of the esophagus ${ }^{11}$; it seems that this technical detail works. The analysis of patients with postoperative RE might offer some insight. In patients undergoing operations in the last 20 years, we always obtained adequate manometric parameters of length and pressure of the antireflux fundoplication. However, some of these patients had esophagitis. We had a group of patients with this complication relatively early after surgical intervention: 5 of 6 patients who had a past history of dyspepsia and peptic disease of the upper gastrointestinal tract had this condition. In 2 older patients esophagitis appeared 184 and 252 months after the operation and several negative endoscopies. In 7 patients esophagitis appeared at least 3 years after surgical intervention; in 2 women the cause was very likely an abnormal increase in body weight. We believe that at least half of these cases of esophagitis are secondary to the usual causes of gastroesophageal reflux disease in an adult population and not to the insufficiency of the fundoplication.

In conclusion, intraoperative manometry helped us to learn how to perform myotomy and how to calibrate the delicate balance between esophagogastric transit and gastroesophageal reflux. The extension of the myotomy to the U-sling-fiber complex of the lesser gastric curvature abolishes the $\mathrm{LES}^{23}$ and treats dysphagia. It is easier to calibrate an antireflux fundoplication than a myotomy, ${ }^{12}$ likely because the gastric component of the LES is quite variable. ${ }^{23}$ Under the name Heller-Dor, many techniques have been described that are in some way different from the others ${ }^{2,3,6,7}$ and from the original operation. ${ }^{8}$ This might be one of the reasons for the controversy. Hopefully, our work will promote further multicentric research studies on common bases.

The senior author (S.M.) acknowledges Dr Frederick "Griff", Pearson, who gave him the opportunity to present the film "Transabdominal myotomy and anterior hemifundoplication with intraoperative manometry", at the Thoracic Surgery Films Session during the 67th Clinical Congress of the American College of Surgeons, held in San Francisco in October 1981.

\section{References}

1. Rebecchi F, Giaccone C, Farinella E, Campaci R, Morino M. Randomized controlled trial of laparoscopic Heller myotomy plus Dor fundoplication versus Nissen fundoplication for achalasia: long-term results. Ann Surg. 2008;248:1023-30.

2. Richards WO, Torquati A, Holzman MD, Khaitan L, Byrne D, Lutfi R, et al. Heller myotomy versus Heller myotomy with Dor fundoplication for achalasia: a prospective randomized double-blind clinical trial. Ann Surg. 2004;240:405-15.

3. Campos GM, Vittinghoff E, Rabl C, Takata M, Gadenstatter M, Lin F, et al. Endoscopic and surgical treatments for achalasia: a systematic review and meta-analysis. Ann Surg. 2009;249:45-57. 
4. Lyass S, Thoman D, Steiner JP, Phillips E. Current status of an antireflux procedure in laparoscopic Heller myotomy. Surg Endosc. 2003;17:554-8.

5. Zaninotto G, Costantini M, Rizzetto C, Zanatta L, Guirroli E, Portale G, et al. Four hundred laparoscopic myotomies for esophageal achalasia: a single centre experience. Ann Surg. 2008;248:986-93.

6. Patti MG, Fisichella PM. Laparoscopic Heller myotomy and Dor fundoplication for esophageal achalasia. How I do it. J Gastrointest Surg. 2008;12:764-6.

7. Finley CJ, Kondra J, Clifton J, Yee J, Finley R. Factors associated with postoperative symptoms after laparoscopic Heller myotomy. Ann Thorac Surg. 2010;89: 392-6.

8. Mattioli S. Dor repair. In: Pearson FG, ed. Esophageal surgery. New York: Churchill Livingstone; 1995. p. 331-8.

9. Di Simone MP, Felice V, D’Errico A, Bassi F, D'Ovidio F, Brusori S, et al. Onset timing of delayed complications and criteria of follow-up after operation for esophageal achalasia. Ann Thorac Surg. 1996;61:1106-11.

10. Ruffato A, Mattioli S, Lugaresi ML, D'Ovidio F, Antonacci F, Di Simone MP. Long-term results after Heller-Dor operation for oesophageal achalasia. Eur $J$ Cardiothorac Surg. 2006;29:914-9.

11. Faccani E, Mattioli S, Lugaresi ML, Di Simone MP, Bartalena T, Pilotti V. Improving the surgery for sigmoid achalasia: long-term results of a technical detail. Eur J Cardiothorac Surg. 2007;32:827-33.

12. Mattioli S, Di Simone MP, Bassi F, Pilotti V, Felice V, Pastina M, et al. Surgery for esophageal achalasia. long-term results with three different techniques. Hepatogastroenterology. 1996;43:492-500.

13. Rice TW, McKelvey AA, Richter JE, Baker ME, Vaezi MF, Feng J, et al. A physiologic clinical study of achalasia: should Dor fundoplication be added to Heller myotomy? J Thorac Cardiovasc Surg. 2005;130:1593-600.

14. Gozzetti G, Mattioli S, Spangaro M, Pilotti V. Management of achalasia: transabdominal myotomy and anterior hemifundoplication with intraoperative manometry. Video available at: www.facs.org; 1988. Chicago: American College of Surgeons; 1988.

15. Gozzetti G, Mattioli S, Di Simone M, Pilotti V. Management of esophageal achalasia: laparoscopic Heller myotomy and Dor anterior hemifundoplication procedure with intraoperative manometry. Video available at: www.facs.org; 1994. Chicago: American College of Surgeons; 1994.

16. Gozzetti G, Mattioli S, Di Simone MP, Felice V, Pilotti V, Lazzari A, et al. [Intraoperative esophageal manometry]. Minerva Chir. 1991;46(suppl):195-200.

17. Litle VR. Laparoscopic Heller myotomy for achalasia: a review of the controversies. Ann Thorac Surg. 2008;85(suppl):S743-6.

18. Possati L, Bragaglia RB, Mattioli S. Results of the surgical management of achalasia. In: Stipa S, Belsey RHR, Moraldi A, eds. Medical and surgical problems of the esophagus. London: Academic Press; 1981. p. 281-3.

19. Engstrom C, Lonroth H, Mardani J, Lundell L. An anterior or posterior approach to partial fundoplication? Long-term results of a randomized trial. World J Surg. 2007;31:1221-7.

20. Herbella FA, Oliveira DR, Del Grande JC. Eponyms in esophageal surgery. Dis Esophagus. 2004;17:1-9.

21. Ellis FH Jr, Kiser JC, Schlegel JF, Earlam RJ, McVey JL, Olsen AM. Esophagomyotomy for esophageal achalasia: experimental, clinical, and manometric aspects. Ann Surg. 1967;166:640-56.

22. Liebermann-Meffert D, Allgower M, Schmid P, Blum AL. Muscular equivalent of the lower esophageal sphincter. Gastroenterology. 1979;76:31-8.

23. Mattioli S, Pilotti V, Felice V, Di Simone MP, D’Ovidio F, Gozzetti G. Intraoperative study on the relationship between the lower esophageal sphincter pressure and the muscular components of the gastro-esophageal junction in achalasic patients. Ann Surg. 1993;218:635-9.

24. Ellis FH Jr. Oesophagomyotomy for achalasia: a 22-year experience. Br J Surg. 1993;80:882-5.

25. Chapman JR, Joehl RJ, Murayama KM, Tatum RP, Shi G, Hirano I, et al. Achalasia treatment: improved outcome of laparoscopic myotomy with operative manometry. Arch Surg. 2004;139:508-13.

\section{Discussion}

Dr Bryan Meyers (St Louis, Mo). I have nothing to disclose. I had the chance to meet Dr Mattioli on Saturday and we discussed his work. I can assure you that he has got a great passion for the treatment of benign esophageal disease. He might have passion for everything, but he definitely has passion for the treatment of benign esophageal disease. In general, we agree on the vast majority of the paper. I, too, embrace the Heller-Dor as the operation of choice. So I'll start with $92 \%$ agreement with you and then just focus on the $8 \%$ where we might differ. I would say that in your presentation and in your paper it was not made clear to me the value of intraoperative manometry, how many times an additional intervention was made, and because I don't do it, I view that as a burden, and I also think it's probably not very necessary, but maybe you can tell us why intraoperative manometry ought to be included as part of this operation.

Dr Mattioli. Thanks a lot. In the first 100 cases, intraoperative manometry was tremendously necessary because we learned how to do the operation. Later on, it was very useful to obtain in each patient the reference values of pressure and length of the Dor we had calculated in the first period looking after postoperative dysphagia and reflux symptoms and esophagitis. Now I joke with my residents and I declare the values of length and pressure before the manometric pull-through is performed. I understand that not everyone can do this technique. So my message is to look at what we have been doing, read and think that that could be the right way.

Dr Meyers. So because you did it for the first 100 cases, then we can learn from you and maybe we don't have to do it with every case.

Dr Mattioli. Yes, yes, but what we can draw from the intraoperative manometry is, one, the complete abolition of the U-fibers and, two, to do a good Dor.

Dr Meyers. One of the beautiful things about the Heller-Dor is the simplicity of the operation. With no mobilization of the complete hiatus and no mobilization of the greater curvature of the stomach, it's a very simple, straightforward operation, but with the 6 to 8 sutures on each side, you have made it a lot more complex than I seem to be doing, and I just wonder if you can justify all those extra sutures. I can generally do a Heller-Dor with 3 sutures and then feel quite good about helping the patient with a durable and useful operation.

Dr Mattioli. I know. I have reviewed the recent literature. Many surgeons don't do the Dor operation. They perform a Dor-like operation. The Dor operation is 6 stitches for each row. This is a good message for the young surgeons. The Dor works without dividing the gastrosplenic ligament, without dividing the short vessels. It is the tension created between the spleen and the stitches that creates the new high-pressure zone. If you apply only 3 stitches, you don't have enough tension. I have hundreds of manometric traces to show that. So my message is to do exactly what Dr Dor did and you will have great results. I have duplicated length and pressure in all cases. For this reason, I can say that probably $7 \%$ postoperative reflux and esophagitis in the long-term reflux is not due to insufficiency of the Dor but may be due to ageing, increased body weight, stress, etcetera. So there will be another way to judge our work in comparison with the medical or endoscopic therapy.

Dr Hiran Fernando (Boston, Mass). What is your approach to the megaesophagus or the sigmoid esophagus, and how many patients in your series actually had a megaesophagus and what were their outcomes?

Dr Mattioli. There were 40 patients in total. I did 50\% in the open series, I did the pull-down; in all 7 patients of the last series, laparoscopic, $100 \%$. And that trick works. You verticalize the axis.

Dr Keith Naunheim (St Louis, Mo). Dr Mattioli, that was a great talk. Like Bryan Meyers, I'm guilty of doing a Dor-like procedure. I use 3 or 4 stitches on either side. So far I have not seen a lot of reflux, 
but that's something we certainly will look for. It may very well be in the manuscript, I didn't see it in the talk, but I wanted to ask you about the extent of your myotomy. Pellegrini and some others have made it clear that going through the gastric sling fibers, 1 or $2 \mathrm{~cm}$ onto the esophagus is really necessary to optimize the relief from dysphagia, but I'm wondering about the proximal extent of your myotomy. Do you take it $4 \mathrm{~cm}$ up? Is your total myotomy $6 \mathrm{~cm}, 8$ $\mathrm{cm}, 10 \mathrm{~cm}$ ? The prospect of the, quote, "long myotomy,', which when we learned it, the inferior pulmonary ligament is divided and we go from the arch of the aorta down, has really sort of gone by the wayside, and for most people I think probably a 6-cm myotomy is enough. I don't know if I'm wrong in that, but you have got a great deal of experience and I thought you could tell me.

Dr Mattioli. Yes, this is a very good question. We did studies before Pellegrini that we have to divide the U-fibers. We passed it through the Ellis operation. It is useless to go too far cranially, because if you look after the intraoperative manometry, the sphincter is $3 \mathrm{~cm}, 3 \mathrm{~cm}$ of esophagus plus $1.5 \mathrm{~cm}$ of lesser gastric curvature. So you need only $5 \mathrm{~cm}, 6 \mathrm{~cm}$ in total for the myotomy. And if you want to cover the myotomy completely, the apex of the myotomy is not to be over the apex of the diaphragm, so you close it without tension. It's a very detailed operation.
Dr F. Griffith Pearson (Mansfield, Ontario, Canada). I would first comment to the two discussants, Dr Meyers and Dr Naunheim, that it's difficult to make the observations that Dr Mattioli has made unless you have been doing the operation for 30 years and have followed the patients, and I'm quite sure you don't have that follow-up yet. It takes a long time in achalasia to see what happens to those patients. For the first 10 to 15 years, most surgeons think they are wizards, and then it begins to deteriorate. I wanted to ask you, Sandro, if you still on occasion modify the surgery at the time of surgery because the motility values aren't what you want them to be. Do you ever at this stage in your experienced career find that you don't get the perfect value you want and you therefore take something down and modify it? That would be a reason for using motility, even if it's only for a small percentage of cases.

Dr Mattioli. Thank you, Dr Pearson. Actually, you taught me to follow up the patients. It's a long story. Yes. We calibrate, in fact, the Dor with the manometry according to the characteristics of the case, but, you know, when you have a dead esophagus, you know you have to reach that kind of parameter, which is $4 \mathrm{~cm}$ of length and $12 \mathrm{~mm} \mathrm{Hg}$, and you give or cut stitches until you get the right measure. Now, I can do that because I have done 200 cases, but for my residents, it's terribly important that they learn. 